\section{Список литературы}

1. Летопись наместников, келарей, казначеев, ризничих, экономов и библиотекарей Свято-Троицкой Сергиевой лавры // Летопись занятий археографической комиссии. 1865-1866 гг. - СПб.: Изд. Археографической комиссии, 1868. - Вып. 4. - С. 62-130.

2. Леонид, архим. Сведение о славянских рукописях, поступивших из книгохранилища св. Троицкой Сергиевой лавры в библиотеку Троицкой духовной семинарии в 1747 году (ныне находящихся в библиотеке Московской Духовной Академии) // чОИДР. - М., 1883. - Кн. 4. - С. 1-112; М., 1884. - Кн. 3. - C. 113-264, Кн. 4. - C. 265-296; М., 1885. - Кн. 1. - С. 297-375.

3. Розанова Н.В. Памятники миниатюры Московского круга первой половины XVI века // Древнерусское искусство. Художественная культура Москвы и прилежащих к ней княжеств XIV—XVI вв. - М.: Наука, 1970. - С. 258274.

4. Briquet C.M. Les filigranes. Dictionnare historique des Marcues du papier des leur apparition vers 1282 jusque'n 1600. Avec
39 figures dans le texte et 16,112 fac-similes de filigranes. Leipzig: Verlag von Karl W. Hiersemann, 1923. - T. 1-4. $836 \mathrm{p}$.

5. Лихачевъ Н.П. Палеографическое значение бумажныхъ водяныхъ знаковъ. - Часть III: Альбомъ снимковъ. - СПб.: ОЛДП, 1899.

6. Строев П. Списки иерархов и настоятелей монастырей российския церкви. - СПб.: Изд. Археографической комиссии, 1877. - X + 1056 стб. + 68 стб.

7. Писцовыя книги Московскаго государства / под ред. действительнаго члена Н.В. Калачова. - СПб.: Изд. Императорскаго русскаго географическаго о-ва, 1877. - Ч. 1: Писцовыя книги XVI века. - Отд. 2: Местности губерний: Ярославской, Тверской, Витебской, Смоленской, Калужской, Орловской, Тульской. - $1598+[5]$ с.

8. [Илларий, иером., Арсений, иером.]. Описание славянских рукописей библиотеки Свято-Троицкой Сергиевой лавры. - М.: Изд. ОИДР, 1878. - Ч. 1-3.

9. Ухова Т.Б. Миниатюры, орнамент и гравюры в рукописях библиотеки Троице-Сергиева монастыря // Записки Отдела рукописей. - М.: Изд. ГБЛ, 1960. - Вып. 22. - С. 5-56.

\title{
B.H. MOИCEEB
}

\section{ОБЩЕСТВО СИНХРОНИЗАЦИИ: ЧЕЛОВЕК И ЕГО ЦИФРОВОЙ ПРОФАЙЛ}

Статья посвящена осмыслению новых медиа. Анализируя современную цифровую культуру, автор критикует представление о «виртуальной реальности» как о некой параллельной реальности; он предполагает, что парадигма онлайн — офлайн теряет свою актуальность, а повсеместное проникновение интернет-технологий приводит к синхронизации человека с его цифровым профайлом. Ключевые слова: новые медиа, виртуальная реальность, тело без органов, синхронизация, цифровой профайл, медиафилософия, визуальный поворот, образ.

оследние полтора десятилетия можно смело назвать временем большого взрыва новых медиа. Twitterреволюции и бесконечные фотографии еды в Instagram, сотни незнакомых нам «друзей» на Facebook и постоянные push-уведомления в смартфоне незаметно, но бесповоротно захватили жителя современного мегаполиса. Развитие высоких технологий навсегда изменило самые привычные социальные ритуалы вроде употребления пищи или проезда в общественном транспорте. Естественно, этой экспансии новых медиа уделяют пристальное внимание публицисты и социологи, об этом пишут колонки (очень часто гневные и пессимистичные) и целые книги.

Несмотря на популярность явления и пристальное внимание к нему, знание о новых медиа только формируется. Существенная сложность в описании новых медиа состоит в том, что это невероятно динамичная среда. Актуальные сервисы и технологии трансформируются и устаревают, новые ритуалы видоизменяются в режиме онлайн. Но динамичность - не главная сложность на пути системного осмысления новых медиа. Еще одной проблемой является не столько отсутствие, сколько невозможность сформировать какой-то общий подход или представление о том, чем являются новые медиа и зачем они нужны человеку, по крайней мере, на данный момент. Поэтому для начала следует уточнить, что мы понимаем под этим термином.

Вполне возможно, что количество попыток определить, что такое новые медиа, уже превысило огромный список дефиниций слова «культура». Популяризатор медиафилософии Валерий Савчук пишет об интуитивной ясности и очевидности новых медиа, и с этим сложно не согласиться [1]. Но при всей ясности в научных кругах до сих пор ведутся споры и царит терминологическая неразбериха. 
Стинс и Ван Фухт в статье «Новые медиа» дают крайне неудачное общее определение явлению, но довольно точно подмечают различия старых и новых медиа. Вот некоторые существенные положения их статьи: в отличие от старых новые медиа быстрее, они открыты, немногословны, на смену тексту приходит картинка, на смену публике пользователи [2]. Когда мы говорим о новых медиа, практически всегда подразумеваются интернет-технологии. Но новые медиа - это не только сайты, как можно подумать; с большой долей уверенности к новым медиа можно отнести почти все современные гаджеты, начиная от смартфона и заканчивая «умным» холодильником.

Следующий вопрос, который будет нас интересовать: каково значение новых медиа в жизни человека? Уже упомянутый исследователь В. Савчук говорит о целом медиальном повороте, другие говорят о новых медиа в контексте robotic turn и т. д.

Так или иначе, но этой теме уделяется пристальное внимание, а о связанном с ней «повороте» рассуждают наравне с визуальным поворотом и другими более менее свершившимися в философии фактами.

Мы ежедневно потребляем новые медиа. Утренняя проверка почты, социальных сетей и новостных лент стала такой же неотьемлемой гигиенической репликой, как чистка зубов. Состояние здоровья и физическую форму теперь отслеживает «умный» браслет, который рекомендует для хорошего самочувствия сжечь определенное количество калорий во время занятий спортом. Раз в год прогрессивное человечество меняет старый айфон на новый. Каждый поход в ресторан сродни фотографическому практикуму: в процессе употребления пищи человек фотографирует себя и содержимое своей тарелки. Совершенно очевидно искушение поговорить о потреблении, симулякрах и утрате непосредственности - обо всем том, что во второй половине XX века предрекли человечеству Жан Бодрийар и Ги Дебор.

Одно из важных утверждений состоит в том, что всё есть образ. Идея визуального поворота, провозгласившего онтологичность визуального образа, кажется весьма актуальной в контексте новых медиа. Основной контент Сети - это не текст, а именно картинка, простейшее визуальное послание кодирует и сообщает реципиенту столько же, сколько абзац текста (а то и больше). Описывая визуальный поворот, исследователи утверждают, что мы не просто сообщаемся, мы мыслим образами.

Еще в 70-х Бодрийар писал о природе визуального образа и его нарастающей роли в обществе потребления. Вот типичное рассуждение французского философа о визуальном: «В случае ТВ, например, происходит переход от обозначенных образом событий к потреблению образа как такового (к потреблению его именно в качестве отличного от событий в качестве зрелищной "кулинарной", как сказал бы Брехт, субстанции, которая исчерпывается в ходе самого поглощения и никогда не отсылает вовне).

Образ отличается и в том смысле, что не дает ни видения, ни понимания событий в их специфичности (исторической, социальной, культурной). Он передает их все переинтерпретированными безразлично в соответствии с одним и тем же кодом» [3].

Примерно в то же время Ги Дебор в своем программном «0бществе спектакля» очень похоже рассуждает о природе визуального образа: «0бразы, которые отслаиваются от каждого аспекта жизни, сливаются в одном непрерывном движении, в котором единство этой жизни уже не может быть восстановлено. Реальность, рассматриваемая по частям, разворачивается в своем обобщенном единстве в качестве особого псевдомира, подлежащего только созерцанию. Специализация образов мира оказывается завершенной в ставшем автономным мире образов, где обманщик лжет себе самому. Спектакль вообще, как конкретная инверсия жизни, есть автономное движение неживого» [4]. Также Ги Дебор фиксирует подмену всего на «представление обо всем» - об этом самая первая максима «0бщества спектакля».

Оба выдающихся исследователя как бы наследуют известное еще с платоновских времен пренебрежение визуальным образом как чем-то априори обманчивым. Они не отвергали колоссальное значение визуального и его экспансию - по сути, об этом и написаны их труды. Они предрекли великое предназначение образа, который спустя десятилетия только упрочил свое мировое господство и приобрел новый функционал.

Визуальный характер сетевой коммуникации был замечен давно. Образ идеально решает задачу быстрой доставки большого количества информации от человека к человеку. Так что Интернет вполне можно назвать катализатором визуального поворота. И если образ можно определить как переинтерпретированный знак, более или менее отсылающий к реальности, то цифровое пространство - Интернет - быстро приобрело устойчивый синоним «виртуальная реальность».

Еще в начале нулевых были популярны рассуждения о том, что такое виртуальная реальность, и куда она приведет человека. На тот момент бытовали представления о виртуальной реальности как о противопоставленной «реальной» реальности. Так, Дмитрий Иванов в книге «Виртуализация общества» говорит о виртуальном пространстве как об Ином, параллельном измерении, в которое можно войти и из которого можно выйти [5]. И, надо сказать, у исследователя были основания делать такие выводы. Дело в том, что на тот момент проникновение высоких технологий (особенно в России) было весьма невелико, мобильные гаджеты и портативные компьютеры были привилегией. Пользователь был прикован к своему поначалу громоздкому персональному компьютеру. У простого человека было стационарное устройство, которое включалось и выключалось. То есть человек имел вход и выход из цифрового пространства. Да и сам интерфейс (особенно поначалу) имитировал реальность. Так что, в начале нулевых рассуждения о виртуальной и реальной реальностях были вполне правомерны. Но с тех пор, как опубликована книга Д. Иванова (2000 г.), такая позиция вызывает все больше вопросов и критики, поэтому хо- 
телось бы услышать аргументы в пользу ее защиты, если таковые имеются.

На сегодня становится все более очевидно, что термин «виртуальная реальность», то есть симуляция реальности, утратил свою актуальность. Цифровой сегмент реальности больше никуда не отсылает, из него нельзя выйти. Мобильные устройства обеспечивают почти круглосуточный доступ к Сети, и даже если человек находится в офлайне, push-уведомления укажут на необходимость немедленного возвращения в онлайн. Компьютер прошел стремительный путь эволюции от огромной машины размером с двухэтажное здание и просто увесистой коробки до тонкого ноутбука, карманного смартфона и вообще очков (имеется в виду Google Glass), смысл которых и заключается в практически постоянном подключении и неразрывном контакте. Логика этой эволюции указывает на то, что человек стремится к уничтожению не только парадигмы «виртуальное - реальное» (онато давно почила), но и парадигмы «онлайн офлайн».

Известно, что одним из главных концептов, разработанных Жилем Делёзом и Феликсом Гваттари, был «тело без органов». Под «телом без органов» Делёз и Гваттари понимали виртуальное измерение человека. Виртуальное, конечно, не в смысле цифровых технологий. «Тело без органов, непроизводящее, непотребляемое, служит поверхностью для регистрации всего процесса производства желания» [6].

Впоследствии концепцию «тела без органов» многократно интерпретировали продолжатели Делеза и Гваттари. Так, Ян Бюканан в статье «Deleuze and the Internet» («Делез и Интернет») развивает представление о «теле без органов» в контексте IT-технологий. Бюканан пишет: «Наша кредитная карта и номер социального страхования скажут гораздо больше о нашей личности и месте проживания, чем наш цвет кожи или сведения, о том, где мы ходили в школу, и именно потому, что в последнее время наша "плоть и кровь", в культурном значении, была заменена бестелесным цифровым "профилем"» [7]. Иными словами, наш бескровный цифровой профайл вытесняет наше биологическое тело и становится все более определяющим в вопросах идентичности, нежели, например, цвет кожи и т. п.

Развивая идею «тела без органов» как метафоры виртуального измерения человека, можно утверждать, что, как выразился Бюканан, цифровой профайл человека это тоже своего рода «тело без органов».

Банковские счета, идентификационные номера и прочие сухие данные - это, однако, далеко не всё, что составляет наш цифровой профайл. Д. Иванов в упомяну- той выше книге рассуждает о киберпротезности институциональных форм виртуальной жизни. Это исследование посвящено в большей степени человеку, прикованному к стационарному компьютеру, который мог отсоединиться от своего виртуального протеза. Но за 12 лет технологии шагнули значительно дальше, и теперь сам портативный гаджет с высокоскоростным Интернетом становится своего рода протезом, а безграничное пространство Интернета, которое открывает гаджет, оказывается не симулятором, а продолжением «реальности». Таким образом, гаджет открывает человеку его цифровой профайл, содержащий гораздо больше информации, чем номера счетов и страховок.

Что же содержит цифровой профайл человека? Помимо многочисленных идентификационных данных, принадлежащих государству и корпорациям, огромный
Сегодня можно с уверенностью сказать, что специальное приложение-измеритель, приложение-консультант и т. д. написаны для любой человеческой активности, начиная от чтения книг и заканчивая бегом, сексом и прыжками с парашютом... То есть почти любая человеческая активность либо уже переосмыслена с учетом проникновения новых медиа, либо переосмысляется прямо сейчас

массив информации цифрового профайла составляют визуальные образы. Существенную часть контента социальных сетей, таких как Facebook, «ВКонтакте» и Twitter, составляют фото и видео. А такие сервисы, как Instagram, вообще специализируются только на визуальном контенте. И большинство активных пользователей Интернета вовлечены в эту сетевую активность.

Одной из главных характеристик визуального контента наших цифровых профайлов является витальность и даже гедонизм. Так, один из основных сюжетов сервиca Instagram - еда. Тело и телесность, сексуальность, игры с домашними животными, праздники и физическая активность - вот сюжеты визуальной коммуникации, циркулирующие в наших цифровых профайлах. Если буквализировать метафору Делёза и Гваттари, то мы наполняем жизнью наши бескровные цифровые профайлы, «тела без органов».

Бодрийар в книге «Америка» задолго до появления Instagram и прочих сервисов описал возможные причины витальности современной визуальной коммуникации: «Речь не идет о том, чтобы быть или даже иметь тело, а о том, чтобы быть подключенным к нему. Подключенным к сексу, подключенным к собственному желанию. Быть связанным с вашими собственными функциями, как с различными типами энергии или видеоэкранами. Модный гедонизм: тело представляет собой сценарий, гигиенические реплики которого раздаются среди бесконечных спортивных, тренажерных залов, залов стимуляций и си- 
Мы не беремся прогнозировать, как будут развиваться новые медиа - ранее мы отмечали, что это чрезвычайно динамичный процесс. На данный момент очевидно лишь то, что путь, по которому развиваются новые медиа и человек как один из главных участников процесса, можно назвать путем синхронизации. Синхронизация протекает на двух уровнях. Первый - это частный уровень, на котором синхронизируются человек и его цифровой профайл. Второй уровень - глобальный: синхронизируются цифровые профайлы. Синхронизация человека и его цифрового профайла - это процесс разрушения пространственновременных границ между сетью и пользователем

ду имеет экстаз полароида, суть которого почти в одновременном овладении объектом и его образом, словно реализовалась старая физика, или метафизика света, где каждый объект, повторяя сам себя, порождает двойников, что и запечатлевается на снимке. Это сновидение. Это оптическая материализация магических процессов. Полароидное фото - экстатическая пленка, отслоившаяся от реального объекта» [8]. Если применить это утверждение к условиям медиареальности, в которой реальный объект закавычен, то мы не просто исступленно автореферируемся, мы овладеваем своей новой идентичностью (по

муляций, простирающихся от Венеции до каньона Тюпанг и представляющих собой коллективную бесполую обсессию» [8]. Этот пассаж французского философа ничуть не устарел, несмотря на то, что «Америка» была написана в 1986 году, и вполне применим к вопросу о цифровых профайлах. Если следовать Бодрийару, то сегодня мы подключаемся к нашей собственной витальности, уже задокументированной и трансформированной в цифровом профайле.

Одним из главных стереотипов современной интернет-культуры стал снимок еды, обработанный и выложенный в Instagram. Пожалуй, главным ритуалом, связанным с употреблением пищи, долгое время оставалась молитва. Сегодня фотографирование еды в Instagram стало не менее важным. Исследования ученых Университета Миннесоты и Гарварда показали, что еда, сфотографированная перед употреблением и выложенная в Instagram, кажется людям вкуснее, чем обычная [9]. Очевидно, что человек, заснявший свою пищу и обработавший ее с помощью моментального фильтра, получает наслаждение не только от вкуса. 0н наслаждается своей подключенностью к скорректированному образу еды, к своему витальному желанию.

Точно так же обстоит дело с пухлыми губами, загорелыми ногами и прочими популярными сюжетами визуальных сервисов. Документируя свои привлекательные части тела, обрабатывая их шаблонными фильтрами и получая социальное одобрение в виде лайков, мы подключаемся к собственной усовершенствованной привлекательности. Подобного рода изображения также являются стереотипами, а их производство связано с ритуалами, такими как фото перед зеркалом или в некоторых стандартных позах. Попадая в определенные ситуации, человек знает, что в данный момент возможен ритуал самодокументирования.

В книге «Америка» Бодрийар называет эпоху, о которой пишет, «эпохой исступленной автореференции» и связывает ее с «экстазом палороида». «В этом и состоит особый эффект нашего времени. Ту же самую приро- сути, своей самостью) посредствам создания ее образа.

В «Симулякрах и симуляции» Бодрийар писал о протезе-двойнике, который непременно уничтожает свой оригинал. Интернет-коммуникация когда-то воспринималась учеными именно как протез, сейчас речь идет уже о том, что виртуальной реальности не существует, на смену ей пришла медиареальность, в которой «реальная жизнь» неразрывна с жизнью цифровой. И по мере того, как наше «тело без органов»/цифровой профайл наполняется витальностью посредством многочисленных ритуалов, протезный характер вполне может приобрести уже сам биологический организм.

Мы не беремся прогнозировать, как будут развиваться новые медиа - ранее мы отмечали, что это чрезвычайно динамичный процесс. На данный момент очевидно лишь то, что путь, по которому развиваются новые медиа и человек как один из главных участников процесса, можно назвать путем синхронизации.

Синхронизация протекает на двух уровнях. Первый - это частный уровень, на котором синхронизируются человек и его цифровой профайл. Второй уровень - глобальный: синхронизируются цифровые профайлы. Синхронизация человека и его цифрового профайла - это процесс разрушения пространственно-временных границ между Сетью и пользователем. Поначалу мы говорили о существовании виртуальной реальности как второй реальности, в которую входили и выходили. Когда технология стала более портативной, пространственно-временные границы стали менее значительны - человек начал пользоваться гаджетами в течение дня и носить их с собой. Следующая ступень развития - технологии, которые должны позволять человеку вообще не выходить из Сети.

Лучше всего синхронизацию человека и его цифрового профайла иллюстрируют «умные» очки Google Glass. Пользователи смартфонов часто прибегают к помощи встроенных карт, по которым легко и удобно ориенти- 
роваться на местности. Подвижная точка, которая перемещается по карте, обозначает человека. Чтобы прийти в нужное место, следует просто наблюдать, куда движется точка. В этом привычном процессе есть одно существенное препятствие - человек вынужден отождествить себя с точкой, смотреть на карту целиком. В свою очередь пользователи Google Glass с такой задачей не сталкиваются. Маршрут, составленный «умными» очками, накладывается прямо на реальную улицу. Это значит, что теперь не нужно отождествлять себя с точкой, достаточно просто двигаться по траектории, которая дополняет реальность при помощи очков. Теперь человек по умолчанию становится точкой на карте, и условность тут ни к чему. Если процесс следования по проложенному смартфоном маршруту был прерывистым (для того чтобы перейти дорогу, необходимо было отрывать глаза от гаджета), то в «умных» очках две условные реальности сливаются в одну - медиареальность. Человек перестает отождествлять себя с различными индикаторами в геолокационных и прочих сервисах.

Пример «умных» очков Google Glass - довольно очевидный, но отражающий идею синхронизации. Сегодня можно с уверенностью сказать, что специальное приложение-измеритель, приложение-консультант и т. д. написаны для любой человеческой активности, начиная от чтения книг и заканчивая бегом, сексом и прыжками с парашютом. То есть почти любая человеческая активность либо уже переосмыслена с учетом проникновения новых медиа, либо переосмысляется прямо сейчас. И это тоже проявление синхронизации.

Человек и его цифровой профайл еще не слишком близки к точке синхронии - человек пока впереди. Но «умные» очки, браслеты фиксации физиологических параметров, программируемые протезы и прочие устройства, предоставляющие возможность постоянного подключения к своему профайлу, приобретают невероятную популярность и обозначают общий вектор своеобразной техно-био-эволюции.

Второй уровень синхронизации имеет несколько иную природу, нежели первый. В этом случае синхронизируются уже цифровые профайлы. Активным пользователям Интернета прекрасно известно словосочетание «вирусное видео». Виральность - это характеристика сетевого контента, который почти моментально распространяется между пользователями. Как вирус. Именно за счет виральности любая важная или интересная информация становится достоянием миллиардов людей. Чем дальше развивается Интернет и проникает технология, тем более синхронно пользователи Сети по всему миру получают информацию.

В синхронизирующемся мире человечество не только почти одновременно получает информацию, но и потребляет новые медиа довольно однородно. Взять хотя бы социальный сервис Instagram. Всем известны преобладающие сюжеты этой визуальной соцсети - еда, коты, части тела и его сексуальность, физическая активность - та же телесность, сексуальность и желание, о которых мы упоминали в контексте идеи Бодрийара о подключенности. Эти реплики отличаются только мелочами, деталями, неразличимыми в общем визуальном потоке. Гомогенность сетевого контента - это одна из главных его характеристик. Но в данном случае существенное значение имеет также и контекст, или обстоятельства создания контента. И эти обстоятельства также однородны. Синхронное производство и потребление сетевого контента - это и есть второй уровень синхронизации, происходящей уже не между людьми, а между профайлами.

\section{Список литературы}

1. Савчук В. Медиафилософия. Приступ реальности. - СПб., 2013.

2. Стинс 0., Ван Фухт Д. Новые медиа // Вестник Волгоградского государственного университета. - Сер. 8: Литературоведение. Журналистика. - 2008. - № 7.

3. Бодрийар Ж. Общество потребления. - М., 2006.

4. Дебор Ги. Общество спектакля. - М., 2000.

5. Иванов Д. Виртуализация общества. - СПб., 2000.

6. Делёз Ж., Гваттари Ф. Анти-Эдип: капитализм и шизофрения. - Екатеринбург, 2008.

7. Deleuze and New Technology, ed. Poster M., Savat D. - Edinburgh, 2009.

8. Бодрийар Ж. Америка. - СПб., 2000.

9. Vohs K.D., Yajin Wang, Gino F., Norton M.I. Rituals Enhance Consumption. - Harvard, 2013. 